\title{
Rehabilitation Options for Subjective Tinnitus
}

\author{
Dongchang Kim¹, Jinbae Shin ${ }^{1}$, Kyungju Lee ${ }^{1}$, In-Ki Jin² \\ 'Department of Speech Pathology and Audiology, Graduate School, Hallym University, Chuncheon, Korea \\ ${ }^{2}$ Division of Speech Pathology and Audiology, Research Institute of Audiology and Speech Pathology, College of Natural Science, \\ Hallym University, Chuncheon, Korea
}

\section{주관적 이명의 재활 방법}

김동창 ${ }^{1} \cdot$ 신진배 $^{1} \cdot$ 이경주 ${ }^{1} \cdot$ 진인기 ${ }^{2}$

한림대학교 일반대학원 언어병리청각학과', 한림대학교 자연과학대학 언어청각학부·청각언어연구소 ${ }^{2}$

\begin{abstract}
Purpose: The purpose of this paper is to provide information about rehabilitation options for subjective tinnitus. While there are several clear treatment options for objective tinnitus, there is no clear treatment option for subjective tinnitus. Although many researchers and clinicians have suggested various rehabilitation options for subjective tinnitus, it is still difficult to determine which rehabilitation options are proper because types of subjective tinnitus vary across patients. Methods: While there are several clear treatment options for objective tinnitus, there is no clear treatment option for subjective tinnitus. Although many researchers and clinicians have suggested various rehabilitation options for subjective tinnitus, it is still difficult to determine which rehabilitation options are proper because types of subjective tinnitus vary across patients. Results: Researchers have suggested several rehabilitation options to reduce effects of tinnitus such as depression, stress, and disturbed sleep. Rehabilitation options for subjective tinnitus are counseling, sound therapy, tinnitus retraining therapy, neuromonics, biofeedback, cognitive behavioral treatment, and mindfulness therapy. Conclusion: This paper will provide useful information about various rehabilitation options for subjective tinnitus which can be applicable in clinics.
\end{abstract}

Key Words: Subjective tinnitus, Rehabilitation, Tinnitus treatment options.

Received: August 8, 2016 / Revised: September 18, 2016 / Accepted: October 5, 2016

Correspondence: In-Ki Jin, Division of Speech Pathology and Audiology, College of Natural Science, Hallym University, 1 Hallimdaehak-gil, Chuncheon 24252, Korea

Tel: +82-33-248-2221 / Fax: +82-33-256-3420 / E-mail: inkijin@hallym.ac.kr

\section{INTRODUCTION}

이명(tinnitus)은 라틴어 'Tinnire'에서 유래한 이름으로 'Tinnire'는 '울리다'라는 뜻으로 외부로부터 소리 자극이 없음에도 불구하고 주관적으로 소리를 지각하는 것을 의미한다(Jastreboff, 1990). 기원전 16세기 이집트 17대 왕조 시대 에버스 파 피루스에서는 '귀에서 윙윙거리는 소리'로 이명을 기술한 기록 이 발견되었으며(Kraft, 1998), 기원전 17세기 앗시리아인의 점 토판에서는 이명을 ‘노래를 부르는 형태', ‘속삭이는 형태' 그리 고 '말하는 형태' 3 가지로 분류하였고 각기 다른 치료법이 필요 하다고 기술한 기록이 발견되었다(Yeo, 2011). 고대로부터 시작 된 이명의 치료에 관한 연구는 명확한 기전의 발견을 위해 현재 까지도 활발한 연구가 진행 중이며, 미국, 영국, 호주 등 세계 여 러 나라에서 이명협회가 조직되어 이명의 치료 방법을 연구하
거나 이명의 효과적인 관리를 위한 정보를 제공하고 있다. 또한 이명연구선도회(Tinnitus Research Initiative)와 같은 국제 이 명연구단체가 조직되어 이명과 관련된 전문가들이 공동으로 이명의 원인과 재활법에 대한 연구를 진행하고 있다(Kim et al., 2015).

이명의 유병률은 국가마다 차이는 있지만 비교적 높은 유병 률을 보인다. 미국이명협회에서 보고한 이명 유병률에 따르면 20세부터 69세 사이 인구의 $15 \%$ 인 약 5,000만명 정도가 이명 환자인 것으로 보고하였으며, 그 중 2,000만명은 만성이명을, 200 만명 정도는 매우 심한 이명을 경험하고 있다고 보고하였다 (American Tinnitus Association, 2014). 또한 2013년 영국이명협 회 연차보고서에 따르면, 영국의 경우 성인의 $10 \%$ 가 이명을 가 지고 있으며, 그 중 $10 \%$ 는 우울증, 스트레스, 수면 방해 등으로 인해 심한 고통을 받고 있다고 보고하였다(British Tinnitus As- 
sociation, 2013). 우리나라의 경우, '2012년 국민건강영양조사' 의 보고에 따르면, 이명 유병률은 성인인구의 $21.4 \%$ 인 것으로 나타났다(Korea Centers for Disease Control and Prevention, 2012). 또한 2008년에 약 24만명이었던 이명 환자가 2013년에는 28 만명으로 매년 3.0\%씩 증가하는 것으로 보고되기도 하였다 (National Health Insurance Service, 2015).

이명은 일반적으로 객관적 이명(objective tinnitus)과 주관적 이명(subjective tinnitus)으로 분류할 수 있다(Kreuzer et al., 2013). 객관적 이명은 체내에서 생성된 소리가 실제로 들리는 것을 의미하는데 혈류의 격동(turbulence of blood flow)이나 근육 수축 등으로 인해 발생할 수 있으며 검사자도 환자의 이 명소리를 직접 또는 간접적으로 들을 수 있다. 객관적 이명이 생기는 이과적 원인으로는 소음성 난청, 노화, 이경화증, 돌발 성 난청, 메니에르병 등이 있으며, 신경학적 원인으로는 두부외 상, 경추손상, 다발성경화증 등이 있다(Han et al., 2009). 객관 적 이명의 치료는 주로 원인을 확인한 후 제거하는 방식으로 진 행된다. 예를 들어, 외경동맥 동정맥루에서 발생한 박동성 이명 은 색전술을 시행하여 치료하거나(Hur et al., 2013), 중이근 경 련에 의해 발생한 이명은 중이근을 절제하는 방식으로 치료가 이루어진다(Park et al., 2007).

주관적 이명은 이명을 않고 있는 본인만이 이명을 지각할 수 있으며, 이명소리의 특징은 귀뚜라미 소리와 같은 고주파수 형 태의 이명에서부터 저주파수 형태의 이명까지 다양한 주파수 적 특징으로 나타날 수 있으며, 지속적 이명으로 나타나기도 하 고 간헐적 이명으로 나타나기도 하여 이명의 원인과 치료법을 정형화하기 어려운 특성이 있다(Møller, 2011). 객관적인 이명 과는 다르게 직접적인 원인의 제거가 어려운 주관적 이명의 경 우, 환자들은 좌절, 짜증, 분노, 불안, 우울, 난청, 과민청각, 불면 증, 그리고 집중력 장애 등의 증상이 유발될 수 있어 이명환자 들의 삶의 질에도 큰 영향을 끼치는 것으로 나타난다. 미국이명 협회가 약 1,100 명의 주관적 이명환자들을 대상으로 이명이 삶 에 미치는 영향에 대한 설문 조사를 실시한 결과, 짜증(34\%), 수면 방해(18\%), 집중력 저하(16\%), 불안(13\%), 우울증(7\%), 사 회적 고립감 $(7 \%)$ 등이 이명환자들의 생활에 영향을 미치는 것 으로 나타났다(American Tinnitus Association, 2014). 주관적 이명환자들을 대상으로 삶의 질에 대한 이명의 영향을 보고한 또 다른 연구에 의하면, 난청과 이명의 지속 기간이 이명과 유의 한 양의 상관관계를 보이는 것으로 나타났다(Alhazami et al., 2016).

환자의 삶의 질에 심각한 영향을 끼칠 수 있는 주관적 이명 을 치료하기 위한 여러 전문가들의 노력에도 불구하고 아직까지 주관적 이명의 기전이 명확하게 밝혀지지 않아 주관적 이명을 확실하게 치료하는 방법은 없다(Kim \& Choi, 2011; Wolever et al., 2015). 그러나 이명소리에 대한 심리적인 스트레스를 줄이거 나 주관적 이명으로 인해 발생할 수 있는 이차적 영향(짜증, 수 면 방해, 집중력 저하 등)을 최소화하기 위한 다양한 재활 방법 들이 제시되었다(Beck, 2011; Jastreboff, 1990; Tyler, 2007). 본 종설은 주관적인 이명의 영향을 최소화하기 위해 제안된 재활 방법들을 소개하여 임상에서 적용 가능한 다양한 재활 옵션에 대한 정보를 제공하고자 한다.

\section{METHODS AND RESULTS}

주관적 이명의 재활을 위해서 그동안 보고된 다양한 재활 방법들 중 상담, 소리치료, 이명재훈련, 인지행동치료, 뉴로모닉 스(neuromonics), 바이오피드백(biofeedback), 그리고 마음집 중 치료(mindfulness)를 소개하고자 한다.

\section{상담(counseling)}

상담은 이명재활에서 매우 중요한 역할을 차지하고 있다. 본 연구에서 소개하고자 하는 주관적 이명의 재활 방법들 중 소리 치료, 이명재훈련, 뉴로모닉스, 바이오피드백 훈련 및 인지행동 치료는 재활 과정에서 상담세션을 포함하고 있으나 상담 그 자 체로 하나의 재활법으로서 역할을 할 수 있다.

Henry et al.(2007)은 269명의 재향군인 이명환자들을 '상담 을 통하여 정보를 제고한 그룹(94명)' '상담이나 교육 없이 그룹 토의만 실시한 그룹(84명)', 그리고 '아무런 재활도 실시하지 않 은 그룹(91명)'으로 나누어 재활 전 및 재활시행 3, 6개월 후의 Tinnitus Severity Index (TSI) 점수를 비교하였다. TSI는 12개 문항으로 이루어져 있는 48점 만점의 설문지로 점수가 높을수 록 이명이 심각함을 나타내는 설문지이다(Folmer \& Carroll, 2006). 연구 결과, 상담을 실시한 그룹에서만 기간에 따른 TSI 점수의 유의미한 변화가 나타났다. Lee et al.(2004)은 이명환 자들을 대상으로 상담만을 실시하여 이명재활의 효과를 분석 하였는데, 상담 전 77\%(SD: \pm 29$)$ 였던 이명 인지 정도가 상담 실시 3 6개월 후에는 53\%(SD: \pm 31)로 감소하였고, 이명의 주 관적 크기와 이명에 의한 괴로움의 정도 및 이명이 생활에 미 치는 영향의 정도가 통계적으로 유의한 수준으로 감소하였다. 3 개의 하위 항목(정서적 스트레스, 기능적 장애, 재앙화)에 따 른 25개의 질문으로 이루어진 Tinnitus Handicap Index (THI) 설문지도 실시하였는데(Newman et al., 1996), THI의 모든 하 위 항목의 점수 역시 감소하여 상담 후에 통계적으로 유의한 차이를 보였다. 이러한 연구 결과들은 상담이 이명재활의 중요 한 요소일 뿐 아니라 상담만으로도 재활의 효과가 나타날 수 있음을 보여주었다.

상담 과정을 통해 이명을 겪고 있는 환자 및 환자 가족들이 
이명에 대하여 이해하고, 이명에 대처하는 방법에 대해 숙지하 도록 하는 것은 중요하다. 이명이 심해지면 이로 인한 고통이 증가하고, 고통의 증가로 인한 스트레스는 우울증이나 불안으 로 이어져 고통에 대한 적절한 대응 전략을 구사하기 어렵게 만든다. 그 결과 이명은 더욱 악화되고, 악화된 이명으로 인해 우울증이나 불안이 더 커지는 악순환으로 이어질 수 있다. 상 담은 이렇게 형성된 악순환의 고리를 끊어 우울증이나 불안의 수준을 낮추어 이명에 더욱 잘 대처하는 선순환의 구조를 구 축하는 데 도움을 줄 수 있다(Searchfield et al., 2010). 이명에 관한 용어의 오해와 혼동이 있으면 이명환자 및 가족들은 이명 을 수용하는 데 있어서 수동적이 되어, 이명재활의 수행에 부정 적인 영향을 미칠 수 있다. 따라서 이명 전문가는 이명 환자 및 가족들을 대상으로 이명에 대한 교육과 이명재활에 대한 가이 드를 지속적으로 병행하여야 한다. 난청을 동반한 이명환자를 상담할 때는 이명에 대한 설명과 함께 난청의 정도 및 유형 등 난청과 관련된 정보, 보청기 및 청각보조기기에 대한 정보도 함 께 제공하여야 한다. 또한 Tunkel et al.(2014)이 제시한 '이명에 대한 임상가이드라인은 상담 시 이명과 난청의 연관성, 이명 관 리에 긍정적 혹은 부정적 영향을 끼칠 수 있는 생활방식의 요소 들, 소음으로부터의 청력 보호, 소음성 난청과 이명의 관계 등을 설명하도록 권고하였다. 또한 이명의 정의, 귀에 들리는 일과성 (transient) 소음과 구별되는 이명, 이명의 평가 및 난청과의 연관 성, 일시적 이명, 이명과 약, 이명에 대한 근본적 치료법의 부재, 이명의 병리학적 생리(pathophysiology)에 대한 현재의 이론 등 이 상담세션에 포함될 수 있다(Tunkel et al., 2014).

\section{소리치료(sound therapy)}

'소리치료(sound therapy)'는 이명 치료의 가장 대표적인 재 활 방법이며 가장 효과가 좋은 방법 중 하나이다(Del Bo et al., 2010). 이명치료에서의 '소리치료'는 외부 소음을 이용하여 이명 소리를 차폐함으로써 이명에 대한 환자들의 인식이나 반응을 수정하는 데 이용된다. '차폐를 통한 치료'는 이명의 크기를 줄 여주고, 이명에 대한 집중을 분산시켜준다(Tyler, 2007). 차폐는 이명 소리 전체를 자극음으로 차폐하여 이명소리가 들리지 않 게 하는 완전 차폐(total masking)와 자극음이 이명소리를 부 분적으로 덮는 부분 차폐(partial masking)로 나눌 수 있다.

Tyler et al.(2012)은 이명환자들을 상담만 받은 집단, 상담과 완전차폐 방식을 적용한 집단, 상담과 부분차폐 방식을 적용한 집단으로 나누고 이명재활 전과 재활 완료 12 개월 후의 Tinnitus Handicap Questionnaire (THQ) 점수를 비교하여 소리 치료를 통한 이명재활의 효과를 평가하였다. THQ는 27 개 항 목으로 구성된 설문지로 높은 점수일수록 이명으로 인한 어려 움이 큰 것을 의미한다(Kuk et al., 1990). 연구 결과, 상담만 받
은 집단은 18 명 중 3 명이 효과가 있었으며 $\mathrm{THQ}$ 점수는 $16.7 \%$ 감소하였다. 완전차폐 집단은 11 명 중 4 명이 효과가 있었으며, $\mathrm{THQ}$ 점수는 $36.4 \%$ 감소하였고, 부분차폐 집단은 19 명 중 6 명 이 효과가 있었으며, THQ 점수는 $31.6 \%$ 감소하였다. 이를 통해 상담만 받은 집단에 비해 상담과 소리치료를 받은 집단의 이명 재활 효과가 더 좋았으나, 완전차폐와 부분차폐는 거의 동등한 효과를 보이기 때문에 이명 습관화를 위하여 부분차폐에 너무 초점을 맞추지 말 것을 권고하였다. 소리치료를 위해 소요되는 시간에는 개인차가 있지만, 보통 6 8개월을 기준으로 한다. 소 리치료는 소리발생기, 보청기 등 보조기기가 필요하기 때문에 가격을 잘 고려해야 하고 이명의 증상과 청각과민증 유무 등을 자세히 살펴보아야 한다(Del Bo et al., 2010).

\section{이명재훈련(Tinnitus retraining therapy, TRT)}

'이명재훈련'은 Jastreboff(1990)가 제시한 신경생리모델(neurophysiological model)에 기초를 둔 것으로, '감정계·신체반응 계'와 청각계로 이어지는 악순환으로 인해 '이명으로 인한 고통' 이 증가하므로 악순환의 고리를 끊기 위해 이명을 습관화(habituation)하는 이명재훈련 방법이다. 이명재훈련의 훈련 목적은 이명 자체를 없애는 것이 아니라 환자가 이명을 의식하지 않게 하는 것이다. 이명재훈련을 위하여 지시적 상담(directive counselling) 및 소리치료를 병행할 수 있다. 지시적 상담은 이명반응 의 습관화(habituation of reaction)를 유도하기 위해 실시하고 소리치료는 이명 인식의 습관화(habituation of perception) 유 도를 위해 실시한다. 일반적인 소리치료에서는 다양한 차폐강 도(완전차폐, 부분차폐)가 하나의 요소로 활용되지만, 이명재훈 련에서의 소리치료는 이명음에 대한 차폐 강도의 기준을 혼합 점(mixing point)으로 정한다(Tyler et al., 2006).

이명재훈련은 초기면담, 청각학적·내과적 평가, 진단과 치료 범주 분류, 지시적 상담, 소리치료, 추적 관찰 및 상담의 순서로 진행된다. 지시적 상담은 객관적인 지식과 행동에 근거하여 문 제의 분석, 진단, 해결방법을 강구하고 사고와 감정 및 행위를 이성적으로 판단하여 재활을 실시하는 상담기법을 의미한다. 초기면담에서는 $\mathrm{THQ}, \mathrm{THI}$ 등 여러 가지 이명 설문지를 활용 하는데, 이러한 설문지를 통하여 이명의 특성과 정도를 파악하 고 재활의 초점을 설정할 수 있다. 청각학적 평가에는 순음청력 검사, 어음청력검사, 임피던스 검사, 청성뇌간반응 검사, 이음향 방사 검사, 이명도 검사, 불쾌청각수준 검사, 최소차폐수준 검 사, 혼합점 검사 등을 시행할 수 있으며, 이명의 원인이 될 수 있는 내과적 문제점을 찾기 위해 기본적인 내과적 검사를 실시 할 수 있다. 초기면담과 평가를 통하여 얻은 자료를 기초로 진 단 및 치료 범주를 0 4의 다섯 가지로 나누고 어느 범주에 속 하느냐에 따라 치료 방법을 달리한다(Jastreboff \& Jastreboff, 
2000). '범주 0’은 이명의 영향이 크지 않아서 상담만으로도 재 활이 가능한 수준을 의미한다. '범주 1'은 난청은 없지만 이명으 로 인한 삶의 질에 영향을 받는 경우로, 상담과 더불어 소리발 생기(sound generator)를 병행한 재활이 요구되는 수준을 의미 하여, '범주 2'는 난청이 동반된 경우로, 보청기의 사용을 통한 이명의 재활이 요구되는 수준을 의미한다. '범주 3'은 난청은 없 으나 과민청각이 이명과 동반된 경우로 소리치료를 실시하되 청력 역치 수준의 크기로 소리치료를 해야 하는 경우를 의미하 고, '범주 4'는 난청은 없으나 이명과 과민청각 그리고 점화효과 를 가지고 있는 경우로, 다섯 범주 중 가장 치료가 어려운 범주 이다. 소리발생기의 이용 시, 처음에는 청력역치 정도의 크기로 시작하여 필요에 따라 점진적으로 소리의 크기를 증가시키는 방법이 사용되고 있다. 각각의 범주에 속한 환자들이 소리 발생 기를 사용할 때는 주로 백색잡음을 사용하되 하루 6 8시간 정 도 사용하도록 권고하고 있다. 일반적으로 추적관찰은 초기 3 개월간은 1 개월 간격으로, 3 개월 경과 후 12 개월까지는 3 개월 간격으로, 12 개월이 경과한 후부터 24개월까지는 6개월 정도의 간격을 두고 실시한다. 추적관찰을 위하여 내원한 경우 설문지 를 활용하여 증상의 호전 여부를 관찰하고 청각과민인 경우 불 쾌청각수준을 정기적으로 검사할 수 있다.

\section{인지행동치료(cognitive behavioral treatment, $\mathrm{CBT}$ )}

인지행동치료는 1960년대에 Aaron Beck이 개발한 '인지치 료(cognitive therapy)'를 기반으로 개발되었다(Beck, 2011). 인 지치료는 명확하지 않거나 도움이 되지 않는 비기능적인 사고 와 행동들을 수정하여 우울증을 치료하는 심리치료로 주로 사 용되었는데, 이후 인지행동치료는 다양한 범위의 질병의 재활 을 위해 사용되기 시작하였다(Beck, 1964). 이명재활에 있어서 인지행동치료는 이명 소리 그 자체를 없애는 것이 아니라 이명 으로 인한 부정적인 인지적, 정서적, 행동적 반응들을 수정하 는 데 목표를 둔다(Karoline \& Birgit, 2011). 인지행동치료는 '합리적 정서행동 치료(Rational Emotive Behavior Therapy, REBT)' 모델을 기반으로 하고있다. REBT는 인지행동치료의 한 형식이며, 미국 심리치료사인 Albert Ellis가 '합리적·정서 적 치료(rational emotive therapy)'를 1950년대 중반에 제안하 면서 발전되었다(Vernon, 2016). REBT는 ABCDEF 모델을 통 해서 설명할 수 있다. $\mathrm{ABCDEF}$ 중 $\mathrm{ABC}$ 는 'activating event', 'belief' 그리고 'consequence'를 의미하고, DEF는 'disrupting intervention', 'effect', '(new) feeling'를 의미한다. $\mathrm{ABC}$ 가 부적 응 행동을 설명하는 모델이라면 $\mathrm{DEF}$ 는 치료적 과정을 보여준 다. REBT이론에 따르면, 정서적이고 행동적인 결과인 'C'를 만 드는 요인은 어떤 사건이 일어나는 자체인 'A' 때문이 아니라 그 것에 대한 사람들의 신념인 ' $\mathrm{B}$ ' 때문이다. 사람들은 ' $\mathrm{B}$ '에서 합
리적이거나 비합리적일 수가 있는데, 합리적인 생각을 가질 경 우에는 유연하고 논리적인 사고를 가짐으로써 그들의 목표를 성취하는 데 도움을 준다. 비합리적일 경우 현실과 타협하지 않 음으로 인해 우울, 화, 걱정, 분개 등의 감정이 일어나고 폭력, 회피 등의 행동이 나타난다. 이러한 비합리적인 신념이 'B'에서 발생하게 되면, 논쟁을 뜻하는 ‘ $\mathrm{D}$ '의 과정이 필요하다. ‘ $\mathrm{D}$ 는 비합 리적인 신념을 가진 대상자를 합리적인 신념을 가질 수 있도록 도와주는 능동적인 과정이다(Dryden, 2002). ' $\mathrm{D}$ ’를 통해 영향(E) 을 받아서 새로운 감정인 ' $\mathrm{F}$ '의 단계로 넘어갈 수 있다. 이런 과 정을 통해 REBT는 유연하지 않고 고정되어 있는 신념들을 합 리적인 신념으로 대체시키는 데 목표를 둔다(Vernon, 2016).

Cima et al.(2012)은 인지행동치료를 적용하여 재활을 실시 한 그룹과 일반 재활을 실시한 그룹으로 나누어 건강과 관련된 삶의 질(health-related quality of life)을 Health Utilities In$\operatorname{dex}$ (HUI) 점수로, 이명의 심각성(tinnitus severity)을 Tinnitus Questionnaire (TQ) 점수로, 이명의 손상도(tinnitus impairment)를 THI 점수로 평가하였다. 총 4회(재활 전, 재활 후 3,8 , 12 개월)를 측정한 결과, 일반 재활을 실시 한 그룹은 HUI 점수 가 하락했지만, $\mathrm{CBT}$ 를 적용한 재활을 실시한 그룹의 HUI 점 수는 상승하였다. 재활 실시 직전과 재활 후 12 개월을 비교한 결과, 일반 재활을 실시한 그룹의 경우 $\mathrm{TQ}$ 가 6.75점, $\mathrm{THI}$ 가 5.22점 낮아졌으나 $\mathrm{CBT}$ 를 적용한 그룹은 $\mathrm{TQ}$ 점수가 15.96점, $\mathrm{THI}$ 점수가 12.8점 낮아져서 일반재활에 비하여 $\mathrm{CBT}$ 가 보다 효과적인 재활 방법이었음을 보고하였다.

\section{뉴로모닉스(neuromonics)}

뉴로모닉스는 이명에 의하여 대뇌 피질의 재조직화가 일어난 다는 동물연구 및 뇌 영상 연구의 결과를 바탕으로 고안된 이 명재활 프로그램이다(Távora-Vieira et al., 2011). 상담과 소리 치료 두 가지로 구성되어 있는데, 소리치료에는 "치유 음악(relaxation music)'과 '광대역 주파수 소리(broad frequency sound)'를 활용한다. '광대역 주파수 소리'는 '샤워소리'와 같은 환경음을 사용하는데 청각계의 정상적 활동을 복원하기 위하 여 이용된다(Távora-Vieira et al., 2011). 뉴로모닉스는 뇌가 소 리로 인지하는 비정상적인 신경활동인 "뇌가소성 처리의 결과 물이 이명 소리이며, 변연계와 자율신경계가 이명 소리로 인해 생기는 자각 및 불편함을 일으키는데 연관되어 있다는 가설을 세우고 있다. 따라서 상담과 소리치료를 활용한 재활을 통해 이 명에 대한 환자의 반응을 줄여 변연계와 자율신경계로 인한 악 순환의 고리를 끊는데 초점을 두고 있다. 따라서 뉴로모닉스의 재활 목표는 환자가 '이명을 인지하고, 이명에 대해 반응하는 과정'에 대한 변연계와 편도체의 개입을 감소시키는 것이다 (Goddard et al., 2009). 편도체는 변연계에 속하는 구조의 일부 
로서 동기, 학습, 감정과 관련된 정보를 처리하는 데 중요한 역 할을 한다. 뉴로모닉스는 이명에 대한 불쾌한 반응을 일으키는 변연계와 자율신경계의 의식 변화를 위해 치유 음악을 사용하 는데, 이명소리와 음악 소리의 차이점을 이용한다. 이명소리가 일정한 강도를 가지고 지속적으로 들리는 것에 비해 음악은 시 간에 따라 진폭의 변화가 있다. 음악의 진폭이 이명소리의 진폭 보다 작을 때는 이명을 지각하고, 이명소리의 진폭보다 클 때는 이명소리를 차폐하는 과정을 치료 기간 내내 반복함으로써 이 명에 대한 환자의 지각(perception) 정도를 낮추게 하는 것이 재활의 주요 목적이다.

뉴로모닉스의 치료 대상은 다음 조건들을 갖춘 사람이어야 한다(Távora-Vieira et al., 2011). 적어도 한 쪽 귀는 4개 주파 수 $(0.5,1,2,4 \mathrm{kHz})$ 의 청력 역치 평균이 $50 \mathrm{~dB}$ 보다 좋은 사람, Tinnitus Reaction Questionnare (TRQ) 점수가 17점 이상인 사 람, 정상 역동범위를 가진 사람, 이명 소리가 박동성 또는 다양 한 소리가 아닌 사람, 정상수준의 음향자극에 의해 이명이 악화 되지 않는 사람, 메니에르병을 않고 있지 않고 기타 다른 이유로 난청 정도가 크게 변동하지 않는 사람, 그리고 소음 환경으로부 터 잘 보호를 받을 수 있는 사람이 뉴로모닉스를 이용하기에 적 당한 후보군이 될 수 있다(Távora-Vieira et al., 2011). 뉴로모닉 스 치료 후보군이 되기 위해서 평가 점수 17점 이상일 것을 요구 하는 TRQ는 26 개의 검사문항을 가진 설문지로 104 점이 만점이 며, 점수가 높을수록 이명으로 인한 고통이 많은 것을 의미한 다(Lee, 2011). 난청의 정도가 심한 경우 재활의 진행이 늦을 수 있으며, TRQ 점수가 17점 이하인 경우 이명이 삶의 질에 큰 영 향을 끼치지 않으므로 뉴로모닉스 재활의 효과가 적을 수 있다.

재활을 시작하기 전에 $\mathrm{THQ}$ 를 이용하여 이명의 병력 및 성 격, 이명의 영향 등에 대하여 파악한다. 치료 효과를 검증하고 상담 및 재활 계획의 기초을 세우기 위하여 $\mathrm{TRQ}$ 를 기초자료 로 활용한다. 청각학적 검사로는 순음청력검사, 고막운동도 검 사, 잔여억제 등을 실시하는데 순음청력검사의 경우 $12.5 \mathrm{kHz}$ 까지 검사를 한다(Hanley \& Davis, 2008). 전체 재활 기간은 6 8개월 정도가 소요되나 개인에 따라 차이가 있을 수 있다. 일반적으로 재활은 세 단계로 나누어 실시하는데 첫 번째 단계 에서는 소리를 편안한 크기로 맞춘 후 이명이 가장 심한 시간 대에 하루 2 4시간 정도 뉴로모닉스 기기를 사용하도록 한다. 단, 운전 중, 귀 기울여 무언가를 듣고 있을 때, 텔레비전을 볼 때, 기기가 젖을 우려가 있을 때, 심장 박동수가 증가하는 운동 을 할 때는 사용하지 않도록 한다. 첫 번째 단계의 재활 기간은 약 2 4개월 정도이다. 두 번째 단계는 뇌가 이명소리를 배경 소 리로 인식할 수 있도록 돕는 시기로, 약 4개월 정도 지속적으로 뉴로모닉스기기를 사용하도록 한다. 이 시기에도 기기의 소리 는 편안한 크기로 맞추어 사용하도록 한다. 마지막 세 번째 단
계는 이명이 더 이상 문제가 되지 않는 시기이나 이명을 무시하 는 능력이 유지될 수 있도록 주 1 회 이상 기기를 사용하도록 하 는데, 재활을 완전히 멈출 경우 이명이 다시 나타나거나 소리에 대한 내성이 감소할 수 있다(Távora-Vieira et al., 2011).

Távora-Vieira et al.(2011)은 호주와 미국의 6개 이명센터에 서 70명(남성 48명, 여성 22명)의 이명환자를 대상으로 뉴로모 닉스 재활을 실시한 결과 TRQ 점수가 $40 \%$ 이상 감소한 참여자 가 53명으로 전체 참여자의 $75.7 \%$ 였고, 재활 후 36 개월까지 추 적 관찰한 결과 재활 효과가 장기간 지속되었다고 보고하였다.

\section{바이오피드백(biofeedback)}

'바이오피드백'이란 우리 몸에서 발생하는 신호를 정밀한 계 측기기로 측정하여 인간이 이해하기 쉬운 방식으로 바꾸어 환 자가 자신의 생리적 활동의 변화를 확인하면서 신체 활동을 통 제하는 방법을 익히도록 하는 재활 방법이다(Choi, 2012). 다시 말하면 우리 몸의 자율 신경이나 불수의근처럼 자신의 의지로 조절하지 못하는 기능(예를 들어 호흡, 심장박동 등)과 관련된 정보들을 측정하여 환자에게 청각적 또는 시각적 정보로 피드 백을 제공함으로써 환자가 스스로의 의지로 어느 정도 이런 기 능들을 조절할 수 있게 해 주는 방법이다. 바이오피드백의 기본 목표는 이명으로 인한 증상 자체에 대한 스트레스 반응을 가져 오는 지속적 이명이 주기적으로 악화되는 것을 막는 것이며, 이 차 목표는 이완절차(relaxation procedure)를 사용하여 훈련함 으로써 이명의 강도를 낮추는 것이다(Duckro et al., 1984).

바이오피드백은 인지행동치료에서 외상 후 스트레스 정도를 감소시키거나 주의력결핍 과잉행동장애(Attention Deficit Hyperactivity Disorder, ADHD) 아동의 과잉행동이나 충동성을 조절하는 훈련 등에 활용하던 치료방법인데 이명재활에도 적 용하고 있다. 이명의 경우, 이명으로 인한 고통 때문에 발생하 는 혈압, 피부온도 및 근육 긴장감의 변화 등을 청각이나 시각 적 신호로 모니터링하여, 이명으로 인해 생긴 신체적 변화를 조 정하는 훈련을 함으로써 신체 반응을 스스로 조절할 수 있다 는 자신감을 얻어 이명을 이겨내도록 하는 것이다(Dohrmann et al., 2007). 훈련의 목적은 이명이 더 이상 스트레스의 요인이 되지 않아 환자의 신체 반응이 이명으로 인하여 변하지 않도록 하는 것이다. 바이오피드백 재활훈련의 대상이 되기 위해서는 이명 이외의 다른 신체적 문제가 없어야 한다. 바이오피드백의 재활 단계는 배경정보 파악 및 청각학적 평가, 준비단계, 훈련 단계로 나눌 수 있다. 배경정보 수집 시에는 일이나 대인 관계 등 환자가 이명으로 인하여 영향을 받는 요소가 무엇인지를 파 악하고, 전반적인 건강문제도 살필 뿐 아니라 환자가 흥미로워 하는 자극의 종류를 확인하도록 한다. 준비 단계에서는 바이오 피드백에 대한 이해를 주 목적으로 한다. 주로 바이오 피드백에 
대하여 소개하고, 훈련에 사용할 기기에 대한 정보를 제공한다. 스트레스와 건강의 관계, 스트레스에 반응했을 때 일어나는 감 정, 스트레스와 만성질환 등에 대하여 설명하고 이명으로 인해 생기는 문제들이 개선되었을 때 발생하게 될 현상들에 대해 이 야기하여 환자에게 용기를 준다. 환자 자신의 의지가 훈련에 절 대적인 영향을 미친다는 것을 설명하고 동기를 부여하되 지나 치게 비현실적인 목표를 세우지 않도록 설명한다. 준비 단계 후 에는 본격적인 훈련 단계에 들어간다. 훈련단계 초기에는 일주 일에 1 2회 정도 방문하여 30 60분 정도 훈련을 실시한다. 편 안한 상태에서 근전도나 피부온도를 측정하고 기준점을 찾는 다. 이명으로 인해 신체가 긴장하고 있을 때의 신체의 반응을 파악하고, 잔잔한 음악을 듣거나 복식호흡을 하는 등 신체의 긴장을 조절하는 훈련을 한다. 훈련 후에는 훈련 시간 동안 기 록한 바이오피드백 결과를 분석하고, 집에 가서도 하루 10 20 분 동안 스스로 훈련하도록 한다.

\section{마음집중치료(mindfulness therapy)}

마음집중치료는 남방불교의 전통적 수행법인 위빠사나(Vipassana) 명상에서 유래한 용어로(Seo \& Kang, 2015), 우리가 집착하고 있는 몸과 마음의 모든 것에 대한 '알아차림'을 말하 며, 일상생활의 모든 영역을 수행의 대상으로 여기는 것이다. 이 순간 있는 것을 사실 그대로 관찰하고 '알아차림'하면 집착 과 고통이 사라져 몸과 마음이 조화롭고 평화로운 최상의 행 복을 성취하는 원리이다. 위빠사나 수행은 모든 현상이 일어나 고 사라지는 것을 아무런 집착 없이 있는 그대로 관찰하는 것 이다. 위빠사나의 주된 수행 방법은 '걷는 수행(행선)'과 '앉아서 하는 수행(좌선)'이며, 이 두 가지 수행 방법 이외에도 일상생활 에서 현재 일어나는 모든 것을 직관적으로 '알아차림' 하는 과 정을 포함한다. 일반적으로 행선을 먼저 하여 알아차리는 힘, 관찰하는 힘을 강하게 한 뒤에 좌선을 하며 행선과 좌선의 시 간 비율을 동일하게 유지하도록 한다. 수행 기간은 특별히 규정 되어 있지는 않지만 보통 5 10주간 주 1회(약 2시간) 프로그램 으로 진행된다. 만성 이명환자들의 재활 목적으로 마음집중치 료를 실시한 몇몇 선행연구에서 재활 전후 이명설문지를 통해 재활 효과를 확인한 결과 대부분의 환자들에게서 재활의 효과 를 확인할 수 있었다(Gans et al., 2015; Sadlier et al., 2008).

마음집중치료는 제 3세대 심리치료법으로서 이명 외의 질병 을 가지고 있는 환자들에게도 접목할 수 있는 심리적 재활법이 다. 하지만 아직까진 이명재활을 목적으로 하는 마음집중치료 의 연구는 활발히 진행되지는 않고 있는 실정이다. 마음집중치 료는 이명의 재활 목적으로 시행했던 재활 방법에 효과를 보지 못한 만성 이명환자들을 대상으로 실시하는 대안으로 주목받 고 있기 때문에 앞으로 다양한 연구가 진행될 필요성이 있다.

\section{DISCUSSIONS}

이명은 개인적-사회적으로 이명환자의 집중력을 저하시켜 생산성을 낮아지게 하고, 직업활동의 참여를 제한하기도 하며, 난청을 동반한 이명의 경우 신체적 무기력을 일으키고 직업을 잃게 만들기도 하는 등 경제적인 문제를 초래하기도 한다. 뿐만 아니라 개인의 삶의 질에도 영향을 끼쳐 짜증, 수면방해, 집중 저하, 불안, 우울증, 사회적 고립감 등을 느끼게 한다(American Tinnitus Association, 2014). 이러한 이유로 많은 연구자들 이 이명의 치료법에 관심을 가지고 연구해 왔음에도 불구하고, 주관적 이명의 경우 정확한 기전이나 치료법을 발견하지 못하 고 있으며, 아직까지 근본적인 치료법은 없다고 보고하였다 (Tunkel et al., 2014). 따라서 치료의 관점보다는 관리의 관점에 서 접근할 필요성이 있다(Duckro et al., 1984). 근본적인 치료 방법이 없긴 하지만 주관적 이명에 대한 여러 가지 재활 방법이 소개되었는데 본 연구에서는 상담, 소리치료, 이명재훈련, 뉴로 모닉스, 바이오피드백, 인지행동치료 그리고 마음집중치료에 대 하여 살펴보았다. 이러한 재활 방법들은 이명 자체를 없애는 것 보다는 이명으로 인한 고통을 완화시키는 데 목표를 두고 있다.

이명은 한 가지 재활 방법만 활용하는 것보다는 서로 다른 재활 방법을 조합하여 사용하는 것이 더욱 효과적일 수 있다. 그 이유는 이명의 증상은 개인별로 매우 다양하여 하나의 재활 방법만으로 이명과 관련된 기능적 장애나 고통을 모두 다룰 수 없기 때문이다. 또한 서로 다른 재활 방법들이 서로 보완적인 역할을 할 수도 있기 때문이다(Wolever et al., 2015). 예를 들 어 청각전문가가 실시하는 '소리기반 교육적 치료(Sound Based Education)'와 심리치료사들이 주로 시행하는 $\mathrm{CBT}$ 를 결합하 면, 환자가 이명으로 인한 증상들을 호전시키거나 악화시키는 원인들에 대해 탐구할 기회를 갖게 되고, 청각학과 심리학이라 는 서로 다른 학문의 관점에서 자신의 이명에 대한 분석을 통 하여 이명에 대해 이해할 수 있도록 도움을 줄 수 있다. 서로 다른 재활 방법들을 병행함으로써 시너지 효과를 얻을 수 있 는 것이다(Philippot et al., 2012). 임상에서 이명재활을 담당하 는 전문가들이 다양한 재활 방법들의 특징, 절차 및 재활 시행 대상의 조건 등에 대한 충분한 정보를 기반으로 해당 이명환자 에게 특화된 재활법들을 조합하여 재활을 시행한다면 이명재 활의 효과를 향상시킬 수 있을 것이다.

본 종설에서는 이명재훈련, 뉴로모닉스, 바이오피드백, 인지 행동치료 등 다양한 주관적 이명의 재활법들을 소개하였다. 상 담과 소리치료는 독립적인 하나의 재활법으로 활용될 수도 있 고 다른 재활법들에서 하나의 구성요소로서 활용될 수도 있다. 또한 각기 다른 특성을 가진 둘 이상의 재활법들을 병행하였을 때, 그 조합이 이명환자의 인지적 특성 또는 이명 특성에 따라 
시너지 효과가 나타날 수도 있다. 하지만 다양한 재활법들 중 다양한 특성이 고려되어야 하는 주관적 이명환자 개개인에 최 적화된 재활법을 선택하는 데 있어 명확한 가이드라인은 없다 고 할 수 있다. 따라서 향후 각 이명환자의 이명특성, 청각적 정 보, 인지적 정보 등을 기반으로 효과적인 이명재활법들을 안내 할 수 있는 가이드라인이 개발된다면 더욱 효과적인 이명재활 이 이루어질 수 있을 것이다.

중심 단어 : 주관적 이명·재활·이명치료옵션.

\section{REFERENCES}

Alhazmi, F., Kay, T., Mackenzie, I., Graham, K., \& Slumping, V. (2016). An investigation of the impact of tinnitus perception on the quality of life. Journal of Phonetics and Audiology, 2, 113.

American Tinnitus Association (2014). Impact of tinnitus. Retrieved from https://www.ata.org/understanding-facts/impact-tinnitus.

Beck, A. T. (1964). Thinking and depression: II. Theory and therapy. Archives of General Psychiatry, 10(6), 561-571.

Beck, J. S. (2011). Cognitive Behavior Therapy: Basics and Beyond. (2nd ed.). (pp. 19-20). New York, NY: The Guilford Press.

British Tinnitus Association (2013). All about tinnitus. Retrieved from https://www.tinnitus.org.uk/all-about-tinnitus.

Choi, S. W. (2012). Introduction to Neurofeedback. (1st ed.). (pp. 1-8). Seoul: Sigma Press.

Cima, R. F., Maes, I. H., Joore, M. A., Scheyen, D. J., El Refaie, A., Baguley, D. M., et al. (2012). Specialised treatment based on cognitive behaviour therapy versus usual care for tinnitus: A randomised controlled trial. The Lancet, 379(9830), 1951-1959.

Del Bo, L., Baracca, G., Forti, S., \& Norena, A. (2010). Sound stimulation. In A. R. Moller, D. De Ridder, B. langguth, \& T. Kleinjung. Textbook of Tinnitus (pp. 597-604). New York, NY: Springer Science \& Bussiness Media.

Dohrmann, K, Weisz, N., Schlee, W., Hartmann, T., \& Elbert, T. (2007). Neurofeedback for treating tinnitus. Progress in Brain Research, 166, 473-554.

Dryden, W. (2002). Rational emotive behaviour therapy. In W. Dryden (4th ed.). Handbook of Individual Therapy. (pp. 347-372). London: Sage.

Duckro, P. N., Pollard, C. A., Bray, H. D., \& Scheiter, L. (1984). Comprehensive behavioral management of complex tinnitus: A case illustration. Biofeedback and Self-Regulation, 9(4), 459-469.

Folmer, R. L. \& Carroll, J. R. (2006). Long-term effectiveness of ear-level devices for tinnitus. Otolaryngology-Head and Neck Surgery, 134(1), 132137.

Gans, J. J., Cole, M. A., \& Greenberg, B. (2015). Sustained Benefit of Mindfulness-Based Tinnitus Stress Reduction (MBTSR) in adults with chronic tinnitus: A pilot study. Mindfulness, 5(6), 1232-1234.

Goddard, J. C., Berliner, K., \& Luxford, W. M. (2009). Recent experience with the neuromonics tinnitus treatment. International Tinnitus Journal, 15(2), 168-173.

Han, B. I., Lee, H. W., Kim, T. Y., Lim, J. S., \& Shin, K. S. (2009). Tinnitus: Characteristics, causes, mechanisms, and treatments. Journal of Clinical Neurology, 5(1), 11-19.

Hanley, P. J. \& Davis, P. B. (2008). Treatment of tinnitus with a customized, dynamic acoustic neural stimulus: Underlying principles and clinical efficacy. Trends in Amplification, 12(3), 210-222.

Henry, J. A., Loovis, C., Montero, M., \& Kaelin, C. (2007). Randomized clinical trial: Group counseling based on tinnitus retraining therapy. Journal of Rehabilitation Research and Development, 44(1), 21.

Hur, T. H., Kim, H. J., Lee, T. K., \& Sung, K. B. (2013). Pulsatile tinnitus caused by arteriovenous fistula of external carotid artery. Journal of the Korean Neurological Association, 31(1), 59-61.

Jastreboff, P. J. (1990). Phantom auditory perception (tinnitus): Mechanisms of generation and perception. Neuroscience Research, 8(4), 221-254.

Jastreboff, P. J. \& Jastreboff, M. M. (2000). Tinnitus retraining therapy (TRT) as a method for treatment of tinnitus and hyperacusis patients. Journal-American Academy of Audiology, 11(3), 162-177.

Karoline, V. G. \& Birgit, K. (2011). Cognitive behavioral treatment (CBT). In A. R. Møller, B. Langguth, D. DeRidder, \& T. Kleinjung (1st ed.). Textbook of Tinnitus. (pp. 557-561). New York, NY: Springer-Verlag New York.

Kim, D. C., Shin, J. B., Kim, C. H., Park, H. J., \& Kim, J. S. (2015). The current trend in the public service of the tinnitus associations and professional organization in the world. Audiology, 11(2), 91-107.

Kim, S. C. \& Choi, J. Y. (2011). Management of presbytinnitus. Journal of Korean American Medical Association, 54(9), 935-940.

Korea Centers for Disease Control and Prevention (2012). Guide to the utilization of the data from the fifth Korea National Health and Nutrition Examination Survey. Cheongwon: Korea Centers for Disease Control and Prevention.

Kraft, J. R. (1998). Hyperinsulinemia: A merging history with idiopathic tinnitus, vertigo, and hearing loss. The International Tinnitus Journal, 4(2), 127-130.

Kreuzer, P. M., Vielsmeier, V., \& Langguth, B. (2013). Chronic tinnitus: An interdisciplinary challenge. Deutsches Ärzteblatt International, 110(16), 278-284.

Kuk, F. K., Tyler, R. S., Russell, D., \& Jordan, H. (1990). The psychometric properties of a tinnitus handicap questionnaire. Ear and Hearing, 11(6), 434-445.

Lee, H. K., Kim, C. W., Chung, M. H., \& Kim, H. N. (2004). The effectiveness of the directive counseling in tinnitus retraining therapy. Korean Journal of Otolaryngology-Head and Neck Surgery, 47(3), 217-221.

Lee, I. W. (2011). Questionnaire for tinnitus. In Korean Otological Society (1st ed.). Current Opinion on Tinnitus. (pp. 105-111). Seoul: Koonja Publishing Inc.

Møller, A. (2011). Introduction. In: A. Møller, B. Langguth, D, De Ridder, T. Kleinjung (1st ed.). Textbook of Tinnitus. (pp. 3-7). Heidelberg: Springer.

National Health Insurance Service (2015, February 16). Appearance ratio of women for tinnitus is 1.4 times higher than men. Retrieved from http://www.nhis.or.kr.

Newman, C. W., Jacobson, G. P., \& Spitzer, J. B. (1996). Development of the tinnitus handicap inventory. Archives of Otolaryngology-Head and Neck Surgery, 122(2), 143-148.

Park, S. N., Nam, I. C., Shin, J. H., \& Yeo, S. W. (2007). A case of objective tinnitus due to middle ear myoclonus treated by surgical therapy. Korean Journal of Otolaryngology-Head and Neck Surgery, 50(1), 73-75.

Philippot, P., Nef, F., Clauw, L., Romrée, M., \& Segal, Z. (2012). A randomized controlled trial of mindfulness-based cognitive therapy for treating tinnitus. Clinical Psychology and Psychotherapy, 19(5), 411-419.

Sadlier, M., Stephens, S. D. G., \& Kennedy, V. (2008). Tinnitus rehabilitation: A mindfulness meditation cognitive behavioural therapy approach. The Journal of Laryngology and Otology, 122(1), 31-37.

Searchfield, G. D., Magnusson, J., Shakes, G., Biesinger, E., \& Kong, O. (2010). Counseling and psycho-education for tinnitus management. In A. R. Møller, B. Langguth, D, De Ridder, \& T. Kleinjung (1st ed.). Textbook of Tinnitus. (pp. 535-556). New York, NY: Springer-Verlag New York.

Seo, H. S. \& Kang, Y. S. (2015). A phenomenological study on the contents and inducing factors of self-transformation experienced by long-term vippassna meditators. Korea Journal of Counseling, 16(6), 505-528.

Távora-Vieira, D., Eikelboom, R. H., \& Miller, S. (2011). Neuromonics tinnitus treatment for patients with significant level of hearing loss: An adaptation of the protocol. International Journal of Audiology, 50(12), 881-886.

Tunkel, D. E., Bauer, C. A., Sun, G. H., Rosenfeld, R. M., Chandrasekhar, S. S., Cunningham, E. R., et al. (2014). Clinical practice guideline tinnitus. Otolaryngology-Head and Neck Surgery, 151(2 Suppl), S1-S40. 
Tyler, R. S. (2007). Evolving counseling and sound therapies for tinnitus. Feedback, 18(2), 12-17.

Tyler, R. S., Coelho, C., \& Noble, W. (2006). Tinnitus: Standard of care, personality differences, genetic factors. Journal for Oto-Rhino-Laryngology and Its Related Specialties, 68(1), 14-19; discussion 20-22.

Tyler, R. S., Noble, W., Coelho, C. B., \& Ji, H. (2012). Tinnitus retraining therapy: Mixing point and total masking are equally effective. Ear and Hearing, 33(5), 588-594

Vernon, A. (2016). Rational emotive therapy. In D. Capuzzi \& M. D. Stauffer (6th ed.). Counseling and Psychotherapy: Theories and Inter- ventions. (pp. 283-308). Verginia, VA: Wiley \& Sons.

Wolever, R. Q., Price, R., Hazelton, A. G., Dmitrieva, N. O., Bechard, E. M., Shaffer, J. K., et al. (2015). Complementary therapies for significant dysfunction from tinnitus: Treatment review and potential for integrative medicine. Evidence-Based Complementary and Alternative Medicine, 2015. http://dx.doi.org/10.1155/2015/931418.

Yeo, S. W. (2011). Introduction and epidemiology. In Korean Otological Society (1st ed.). Current Opinion on Tinnitus. (pp. 1-21). Seoul: Koonja Publishing Inc. 